\title{
Editorial
}

\section{When to PEG?}

As dysphagia clinicians we strive to maximize the amount of oral intake that can safely and efficiently sustain our patients and therefore maximize their life quality. Although intricately familiar with the various modes of nutritional intake, most of us will lean toward prescribing oral intake if at all possible. Unfortunately, exercising these good intentions is not always possible. At times the severity of our patients' dysphagia is so severe that indeed the safest nutritional route is via tube. As researchers, however, we recognize that no procedure is without risk and that any management goal is usually based on weighing the risks and benefits of all possible options and then recommending the option with least risk and most benefit. From available literature we know that aspiration risk is not completely eliminated with tube feeding. In fact, some research claims that tube feeding can increase aspiration risk rather than reduce it [1]. Other research states that patients who are on restricted thin fluid diets may in fact require tube feedings to combat the risk of dehydration [2]. It is clear that the benefit of tube feeding is still in question. Multisite research is now underway to address the issue of the benefit, or possible lack thereof, of tube feeding [3]. In the meantime, what do we do? How do we decide the optimal nutritional route for our patients?

The article by Wilkinson et al. in this issue [4], has made good preliminary headway in this direction. The authors conducted a retrospective study to determine the patient variables that lead clinicians to prescribe tube feedings, in particular percutaneous endoscopic gastrostomy (PEG). They correctly claim that knowledge of these variables will help predict the eventual need for PEG tubes and thereby allow for earlier insertion which, in turn, will avoid the complications of malnutrition or dehydration. They assess the predictive ability of fluid and food tolerances at specific points along the recovery of acute dysphagic stroke patients. Their two outcomes are the insertion of a PEG at one year poststroke and the presence of dysphagia, measured by the inability to take normal fluids and food textures on day 28 poststroke. The authors claim that, based on their results, intolerance of grade 2 thickened fluids (i.e., thickness of yogurt) at day 7 predicts persistent dysphagia at day 28, and intolerance of grade 3 fluid (i.e, thickness of instant pudding) at day 7 or puree at days 7 or 21 predicts PEG insertion at one year. Assuming these results are correct, the presence of these variables would suggest that clinicians offer patients early PEG insertion. However, determining whether these estimates are correct is not straightforward.

The authors are methodologically diligent in describing, with viscometer readings, the various textures being assessed. They also operationally define what they mean by dysphagia and that it was determined by either clinical assessment or videofluoroscopy. They detail, as best as is possible in a multisite retrospective study, that the decision for PEG insertion was based on "mostly nutritional grounds and in consultation with the patient and his/her family." Reviewers recognize that retrospective studies serve to generate hypotheses and should not be subject to the methodological rigors of a prospective study; however, the manner in which the data were summarized may be skewing the results away from the truest estimate. The authors declared 31 patients to have died by day 21 . They do not, however, state how many had died by day 28 or by one year, which were the endpoints for this study. If one is to assess how select variables can predict a particular outcome in a data set, it is necessary that the outcome is at least possible to occur. Those patients who died before the outcomes were measured may or may not have experienced either dysphagia or PEG insertion if they had lived to either day 28 or one year poststroke. The 
Table 1. How likelihood ratios are generated (adapted from [5])

\begin{tabular}{|c|c|}
\hline & $\begin{array}{l}\text { Measured Outcome } \\
\text { Dysphagia at Day } 28 \\
\text { or } \\
\text { PEG Inserted at } 1 \text { Year }\end{array}$ \\
\hline $\begin{array}{l}\text { Food/Fluid } \\
\text { Intolerance }\end{array}$ & Present \\
\hline Present & $a$ \\
\hline Absent & $\begin{array}{r}\mathrm{d} \\
(b+d)\end{array}$ \\
\hline
\end{tabular}

Sensitivity $=a /(a+c)$

Specificity $=d /(b+d)$

False positive $=1-$ specificity

Likelihood ratio $=$ Sensitivity $/$ False positive

data on dysphagia presence on day 28 appears to have included these patients in the proportion denominators, and, therefore, they were likely counted as successes (i.e., no dysphagia and no PEG, cell $\mathrm{d}$ in Table 1). Handling of the data in this way overestimates the successes and underestimates the false positives, which would overestimate the likelihood ratio (see Table 1). The calculations for PEG insertion are not as transparent and therefore, it is difficult to confirm the accuracy of the reported false positives and likelihood ratios.

It may have been more useful to the reader if the authors described their data differently and according to the method of Feinstein [5]. According to Feinstein, the authors could have categorized food or fluid options in a categorical list and counted patients only at the most unsuccessful level, rather than the cumulative format utilized in this article. In other words, the number of patients who did not tolerate pureed foods would not be included with those who did not tolerate a normal diet. In this way, four distinct categories would be created for each fluid or food (i.e., normal fluid, G1 fluid, G2 fluid, and G3 fluid; likewise, normal diet, soft diet, moderately soft diet, and puree diet). The sensitivity, specificity, false positive, and likelihood ratios could then be calculated for each category and for each day measured (i.e., days 7, 14, and 21). Likelihood ratios should be presented with confidence intervals in order to determine the accuracy of these estimates [6]. These changes would greatly benefit the readers' interpretation and ultimate clinical utilization of these data.

There is good reason to study the variables that would predict eventual need for tube feedings. Research is suggesting that earlier insertion may benefit patients' medical outcomes. Wilkinson et al. have made a first step at not only posing this question but also attempting to solve it; however, the readership continues to await the answer through further well-designed retrospective and prospective studies.

\section{References}

1. Finucane TE, Bynum JP: Use of tube feeding to prevent aspiration pneumonia [see comments]. Lancet 348:1421-1424, 1996

2. Finestone HM, Foley NC, Woodbury MG, Greene-Finestone L: Quantifying fluid intake in dysphagic stroke patients: A preliminary comparison of oral and nonoral strategies. Arch Phys Med Rehabil 82:1744-1746, 2001

3. International stroke trials collaboration-Food. http://www. den.ed.ac.uk/food, 2002

4. Wilkinson TJ, Thomas K, MacGregor S, Tillard G, Wyles C, Sainsburg R: Tolerance of early diet textures as indicators of recovery of dysphagia after stroke. Dysphagia 17:227-232, 2002

5. Feinstein AR: Clinical epidemiology. The architecture of clinical research. Philadelphia: W.B. Saunders, pp 608-609, 1985

6. Sackett DL, Haynes RB, Guyatt GH, Tugwell P: Clinical epidemiology: A basic science for clinical medicine. Vol. 5. Boston: Little, Brown, 1991

Rosemary Martino, MSc, MA

Department of Speech Language Pathology The Toronto Western Research Institute University of Toronto

Department of Speech Language Pathology The Toronto Western Hospital, University Health Network Toronto, Ontario, Canada 